Dublin Institute of Technology

ARROW@DIT

Articles

School of Management

2013

\title{
Optimising End-to-End Maritime Supply Chains: a Carbon Footprint Perspective
}

Patrick Rigot-Muller

University of Newcastle

Chandra Lalwani

University of Hull

John Mangan

University of Newcastle

Orla Gregory

Dublin Institute of Technology, orla.gregory@dit.ie

David Gibbs

Univesity of Hull

Follow this and additional works at: https://arrow.dit.ie/buschmanart

Part of the Business Administration, Management, and Operations Commons

\section{Recommended Citation}

Patrick Rigot-Muller, Chandra Lalwani, John Mangan, Orla Gregory, David Gibbs, (2013) "Optimising end-to-end maritime supply chains: a carbon footprint perspective", International Journal of Logistics Management, The, Vol. 24 Iss: 3, pp.407 - 425, DOI :

10.1108/IJLM-01-2013-0002 


\title{
Optimizing end-to-end maritime supply chains: a carbon footprint perspective
}

\author{
Author Details: \\ Dr Patrick Rigot-Muller \\ Newcastle University \\ Professor Chandra Lalwani \\ Hull University \\ Professor John Mangan \\ Newcastle University \\ Ms. Orla Gregory \\ Dublin Institute of Technology \\ Professor David Gibbs \\ Hull University
}

Structured Abstract:

\section{Purpose}

The purpose of this research is to illustrate an optimisation method, and resulting insights, for minimising total logistics related carbon emissions for end-to-end supply chains.

\section{Design}

The research is based on two real-life UK industrial cases. For the first case, several alternative realistic routes towards the UK are analysed and the optimal route minimising total carbon emissions is identified and tested in real conditions. For the second case, emissions towards several destinations are calculated and two alternative routes to southern Europe are compared, using several transport modes (road, ro-ro, rail and maritime). An adapted Value Stream Mapping (VSM) approach is used to map carbon footprint and calculate emissions; in addition AIS data provided information for vessel specification allowing the use of more accurate emission factors for each shipping leg.

\section{Findings}

The analyses demonstrate that end-to-end logistics carbon emissions can be reduced by between 14\% and 21\% through direct deliveries (to Felixstowe and Southampton) when compared to deliveries with transhipment and warehousing (in Antwerp). For distant destinations the maritime leg of the supply chain is the main contributor to the total emissions. It is notable that one of the main apportionment approaches (that of Defra in the UK) generate 
higher carbon footprints for routes using Ro-Pax vessels, making those not optimal. The feasibility of the optimal route was demonstrated with real-life data.

\section{Originality/Value}

This research used real life data from two UK companies and highlighted where carbon emissions are generated in the inbound and outbound transport chain, and how these can be reduced. The tool employed, VSM, proved to be a flexible tool that can be adapted to measure and analyse CO2 emissions with different calculation methods 


\section{Optimizing end-to-end maritime supply chains: a carbon footprint perspective}

\section{Introduction}

The purpose of this research is to develop optimisation methods for minimising total logisticsrelated carbon emissions for end-to-end supply chain distribution systems. Appropriate tools for calculating the carbon emissions for the maritime leg of global supply chains are discussed. The research is based on real life global supply chain data from two different cases. One case focuses on end-to-end analysis, with mainly inbound flows and local UK distribution, and the other case focuses on outbound distribution flows from the UK to Europe and some worldwide destinations. The analysis of the first case demonstrates that end-to-end logistics related carbon emissions can be reduced by $16 \%$ to $21 \%$ through direct delivery to the UK as opposed to transhipment via a Continental European port. An adaptation of the Value Stream Mapping approach was employed and proved to be a flexible tool that can be adapted to measure and analyse $\mathrm{CO}_{2}$ emissions with different calculation methods. The analysis of the second case shows that deliveries to southern Europe have the highest potential for reduction though deliveries by sea. Both cases show that for distant overseas destinations, the maritime leg represents the major contributor to $\mathrm{CO}_{2}$ emissions in the end-to-end supply chain. The applications of the different calculation methods, which depend on the data available, are presented followed by the discussion on the results.

\section{Literature Review}

With the increased focus on anthropogenic $\mathrm{CO}_{2}$ emissions and climate change, companies are showing an increased interest in managing the climate change risk impact of their activity. The growing number of participating members of the Carbon Disclosure Project's well known Supply Chain report (Carbon Disclosure Project, 2012) illustrates this evolution. In the procurement field, the measuring of carbon footprint within end-to-end supply chains is one of the steps towards answering this concern. Standard methodologies are only just beginning to emerge (GHG Protocol, 2011).

In the academic field, many studies have been conducted aiming to develop appropriate methods for calculating carbon emissions in the context of specific industrial applications. Edwards et al (2009) studied the carbon footprint of the "last mile delivery", and compared emissions between standard and on-line shopping. To assess carbon emissions from road transport they used an approach based on emission factors in $\mathrm{gCO}_{2} / \mathrm{T} . \mathrm{km}$, using data provided by the UK Department of Environment, Food and Rural Affairs (Defra), by its National Atmospheric Emissions Inventory agency (NAEI), by the UK Road Haulage Association (RHA) and the UK Freight Transport Association (FTA). Edwards et al (2009) highlighted the importance of the number of items purchased, showing that for large numbers of items purchased, "standard" traditional shopping is more carbon effective, and for smaller numbers of items on-line shopping and delivery are more effective. This approach (the delivery size), expressed in their study in number of items purchased, will be considered in our paper as the "truck load" expressed in average tonnages and in percentage. Miyoshi and Mason (2009) analysed emissions from airfreight transport, calculating emission factors in 
$\mathrm{gCO}_{2}$ /passenger.km using fuel consumption models and showed that results could change significantly depending on the route selected, and differences in airlines' strategies such as aircraft types used, load factors and aircraft configurations. We can see similar issues in the maritime sector, where emission factors of maritime supply chains are particularly difficult to measure due to a variety of reasons, including different emission factors and apportionment possibilities depending on the vessel type and size, the routes and distances, the number of days at sea and days at port, the fuel choice, the average speed and the average load, as shown for example in Leonardi and Browne (2010) and in Rizet et al (2008). Leonardi and Browne (2010) also highlighted some limitations, such as the uncertainties about the container load and the lack of analysis with regard to the introduction of new technologies on board vessels.

A major report from the IMO (2009) provided an important dataset on emissions factors (vessels emissions in $\mathrm{kgCO}_{2} / \mathrm{T} . \mathrm{km}$ ) by ship type and size. These results where adapted by Defra (2011) as a reference for the UK. In parallel, the industry-led Clean Cargo Working Group approach (CCWG, 2009) also produced emissions factors by trade routes for container vessels (measured in $\mathrm{CO}_{2} / \mathrm{TEU}$ ) based on real fuel consumption. Also, an independent approach led by the Carbon War Room, aims to provide an individual vessel rating, using a methodology that consists in extrapolating the EEDI formula for existing vessels (IMO, 2012). In this study, we have analysed a large number of possible alternative routes, thus we will use an approach based on Defra's emission factors in $\mathrm{gCO}_{2} / \mathrm{T} . \mathrm{km}$, without calculating intermediate steps such as the energy consumption.

With regard to supply chain mapping, modelling and optimisation covering the "End-to-End" supply chain, a number of studies have been carried out recently. Sundarakani et al (2010) propose an approach based on the Lagrangian and Eulerian box model, which aims to cover carbon footprints embedded in products, and they also highlight a lack of detailed industry data available. Ramudhin et al (2008) provide an optimisation method based on linear programming and that takes into consideration carbon trade under a cap-and-trade situation. The application of linear programming methods makes sense when an extremely large number of options are possible, which is not the case in this research. The number of possible, realistic logistic routes is limited and no carbon trading policies are applicable to our cases. Also, Value Stream Mapping (VSM), which is a lean mapping tool originally created to reduce waste and increase productivity from industrial processes (Rother and Shook, 2009), has also been applied in a sustainability context. Lean thinking researchers and practitioners have already defined concepts such as "Sustainable Value Stream Mapping" (Simon and Mason, 2003; Norton, 2007), “Carbon Stream Map" (Windsor, 2010) or the "Voice of Environment Value Stream Mapping” (Olson, 2009). In this paper we propose to investigate the application of VSM to optimise end-to-end maritime supply chains, with specific attention to the construction and formalisation of the VSM databoxes, as we will see in Section4.

\section{Description of the problem}

This research is based on two real life industrial cases, with activity data from 2011 and 2012. The first case concerns inbound flows to the UK, and the second case concerns outbound flows from the UK.

The first case concerns a UK-based distributor of plastic products. Most products for this case company are sourced from the suppliers DCs, located either in the UK or in the EU, but the 
original production facilities are based in Asia and the Middle East. Once sourced, products are stored in a central warehouse in the UK's East Midlands and then shipped to more than 600 delivery points in the UK.

The scope of our analysis is the end-to-end supply chain for the major product sold by the distributor, a high-density resin. This product is manufactured in the production facility in Saudi Arabia and delivered to the final customers in the UK in containers, on pallets and in bulk form. The optimisation levers considered are the study of alternative delivery routes (including direct delivery to the UK) and the UK warehouse location, based on an analysis of the customers' centre of gravity. The company had not carried out supply chain carbon mapping before this research and therefore there were no available supply chain environmental data. All logistics operations (warehousing, upstream and downstream transport) are carried out by logistics service providers. Upstream transport is provided either by transporters (for local sourcing by road) or by freight forwarders (for distant sourcing by maritime transport). The warehousing operations and the final delivery to the customers are provided by the distributor's main logistics service provider based in the East Midlands, who runs the UK warehouse.

The second case focuses on developing a carbon footprint metric for a manufacturer of industrial paints with a production plant in the north of England. The case company has worldwide delivery range, but most flows are concentrated in continental Europe. An interesting aspect of this case is the variety of transport modes used in the supply chain including road transport, containerships, Ro-Ro vessels and rail transport. Some destinations are delivered by two different routes (with two transport modes) which allowed carbon footprint comparisons to be made by mode.

In this research, the emission measure covers only the transport and warehousing operations. This means that indirect emissions such as the distributor's central offices, employee business travel, etc are not included. We have used whenever required emission factors from Defra (2011) which provides the national standards for the UK. We will be using in this paper the expression 'carbon footprint' as a generic synonym for "emissions of carbon dioxide or greenhouse gases expressed in $\mathrm{CO}_{2}$ equivalents” (Wiedmann and Minx, 2008).

Tables 1 and 2 show the routes analysed for cases 1 and 2, respectively. Table 1 illustrates the different selected end-to-end routes from the plant in Saudi Arabia. This table specifies the transport mode for the product collection, the main maritime route, the transhipment port (if applicable), the supplier warehouse in Antwerp (if a warehousing operation is applicable in the specified route), the Ro-Ro route towards the UK (if applicable), the distributor warehouse in East Midlands (if a warehousing operation is applicable in the specified route) and the transport mode for the final delivery. Table 2 illustrates the selected delivery routes from the northern UK production facility to different destinations. Its structure is similar to Table 1, excepted that the flows are outwards oriented and that some changes were made in the table columns representing the main stages, adapted to the flows structure of the second case. 
Table 1: Illustration of inbound routes (case study 1).

\begin{tabular}{|c|c|c|c|c|c|c|c|c|}
\hline \multirow{2}{*}{\begin{tabular}{|c}
$\begin{array}{c}\text { Final Delivery } \\
\text { Location }\end{array}$ \\
\end{tabular}} & \multirow{2}{*}{ Unit Type } & \multicolumn{7}{|c|}{ Route specification } \\
\hline & & Collection & Maritime (main) & Transhipment & Supplier WH & UK Ro-Ro & Distributor WH & Final delivery \\
\hline UK-wide & Container/Pallet & Road & Jeddah - Antwerp & none & Antwerp & Zeebrugge - Purfleet & East Midlands & Road \\
\hline UK-wide & Container/Pallet & Road & Jeddah - Immingham & Zeebrugge & none & none & East Midlands & Road \\
\hline UK-wide & Container/Pallet & Road & Jeddah - Liverpool & Le Havre & none & none & East Midlands & Road \\
\hline UK-wide & Container/Pallet & Road & Jeddah - Antwerp & none & none & Zeebrugge - Hull & East Midlands & Road \\
\hline UK-wide & Container/Pallet & Road & Jeddah - Rotterdam & none & none & Hoek - Harwich & East Midlands & Road \\
\hline UK-wide & Container/Pallet & Road & Jeddah - Antwerp & none & none & Osten - Ramsgate & East Midlands & Road \\
\hline UK-wide & Container/Pallet & Road & Jeddah - Antwerp & none & none & Dunkerque - Dover & East Midlands & Road \\
\hline UK-wide & Container/Pallet & Road & Jeddah - Antwerp & none & none & Calais - Dover & East Midlands & Road \\
\hline UK-wide & Container/Pallet & Road & Jeddah - Antwerp & none & none & Zeebrugge - Purfleet & East Midlands & Road \\
\hline UK-wide & Container/Pallet & Road & Jeddah - Felixstowe & none & none & none & East Midlands & Road \\
\hline UK Newport & Container/Bulk & Road & Jeddah - Antwerp & none & Antwerp & Zeebrugge - Purfleet & none & Road \\
\hline UK Newport & Container/Bulk & Road & Jeddah - Southampton & none & none & none & none & Road \\
\hline
\end{tabular}

Table 2: Illustration of outbound routes (case study 2).

\begin{tabular}{|c|c|c|c|c|c|c|}
\hline \multirow{2}{*}{$\begin{array}{c}\text { Final Delivery } \\
\text { Location }\end{array}$} & \multirow{2}{*}{ Unit Type } & \multicolumn{5}{|c|}{ Route specification } \\
\hline & & Collection mode & UK Rail & Maritime & Transhipment & Final delivery \\
\hline Holland & Sea Container & Road & none & Teesport - Rotterdam & none & Road \\
\hline Sweden & Box/Tanker & Road & none & Immingham - Gothenburg & none & Road \\
\hline Turkey & Sea Container & Road & none & Felixstowe - Gebze & Antwerp & Road \\
\hline Turkey & Trailer & Road & none & Dover - Calais & none & Road \\
\hline Spain & Trailer & Road & none & Dover - Calais & none & Road \\
\hline Italy & Trailer & Road & none & Dover - Calais & none & Road \\
\hline UK (domestic) & Trailer & Road & none & none & none & Road \\
\hline Greece & Sea Container & Road & none & Teesport - Piraeus & Antwerp & Road \\
\hline Greece & Sea Container & Road & Selby - Felixstowe & Felixstowe - Piraeus & none & Road \\
\hline China & Sea Container & Road & none & Teesport - Shanghai & Zeebrugge & Road \\
\hline Korea & Sea Container & Road & none & Teesport - Busan & Zeebrugge & Rail \\
\hline USA & Sea Container & Road & Selby - Felixstowe & Felixstowe - Houston & none & Road \\
\hline Singapore & Sea Container & Road & none & Teesport - Singapore & Zeebrugge & Road \\
\hline Australia & Sea Container & Road & Wakefield - Southampton & Southampton - Brisbane & none & Road \\
\hline India & Sea Container & Road & Leeds - Southampton & Southampton - Chennai & none & Road \\
\hline Brazil & Sea Container & Road & Selby - Tilbury & Tilbury - Rio de Janeiro & none & Road \\
\hline Dammam & Sea Container & Road & Leeds - Southampton & Southampton - Dammam & none & Road \\
\hline
\end{tabular}

\section{Methodology and analysis}

The first main step for this research was to map the end-to-end supply chains. Considering the extent of the scope for analysis, particular attention is given to the geographical location addresses, the transport mode, and the average weight of trips. More specifically, we developed a "current state" value stream map (Rother and Shook, 2009) for case study 1, for which the databoxes will be explained in the following sub-sections. Even though in most cases emissions were assessed using emission factors using the methodology as provided by Defra (2011), when the supplier was able to provide its own emission factors by measuring its own transport fuel consumption or energy consumption in the warehouses, those ones have replaced the Defra's standard values. The approach we used consisted of defining a set of product and packaging data (pallet weight, pallet per container, pallets per lorry trailer) which can be applied to the whole supply chain map, even though for different supply chain stages specific approaches for carbon footprint calculation could be used.

\subsection{Product \& packaging data}

Product \& packaging data contain mainly product weight, size and packaging specifications. In case 1, products are transported in containers and most of them are palletised. Each 40 -foot container is able to transport 18 pallets weighing on average 1.375 Tonnes, representing 24.75 Tonnes in each loaded container. This information is useful in that it allows conversion of weight data into logistics units (trucks, containers) and vice-versa, and then uses the 
appropriate emission factors, which can be based on both weight and transport unit. In case 2, the situation was more diverse, due to the analysis of several routes (with different transport means) and many products (with different densities). As a consequence we tried to avoid using a single average truck load. We collected the detailed weight for every shipment (either in containers or in trucks) and thus the exact information in terms of number of shipments and truck load could be used for each shipment. Figure 1 illustrates the average weight for each route (all departing from the same production facility in the north of England).

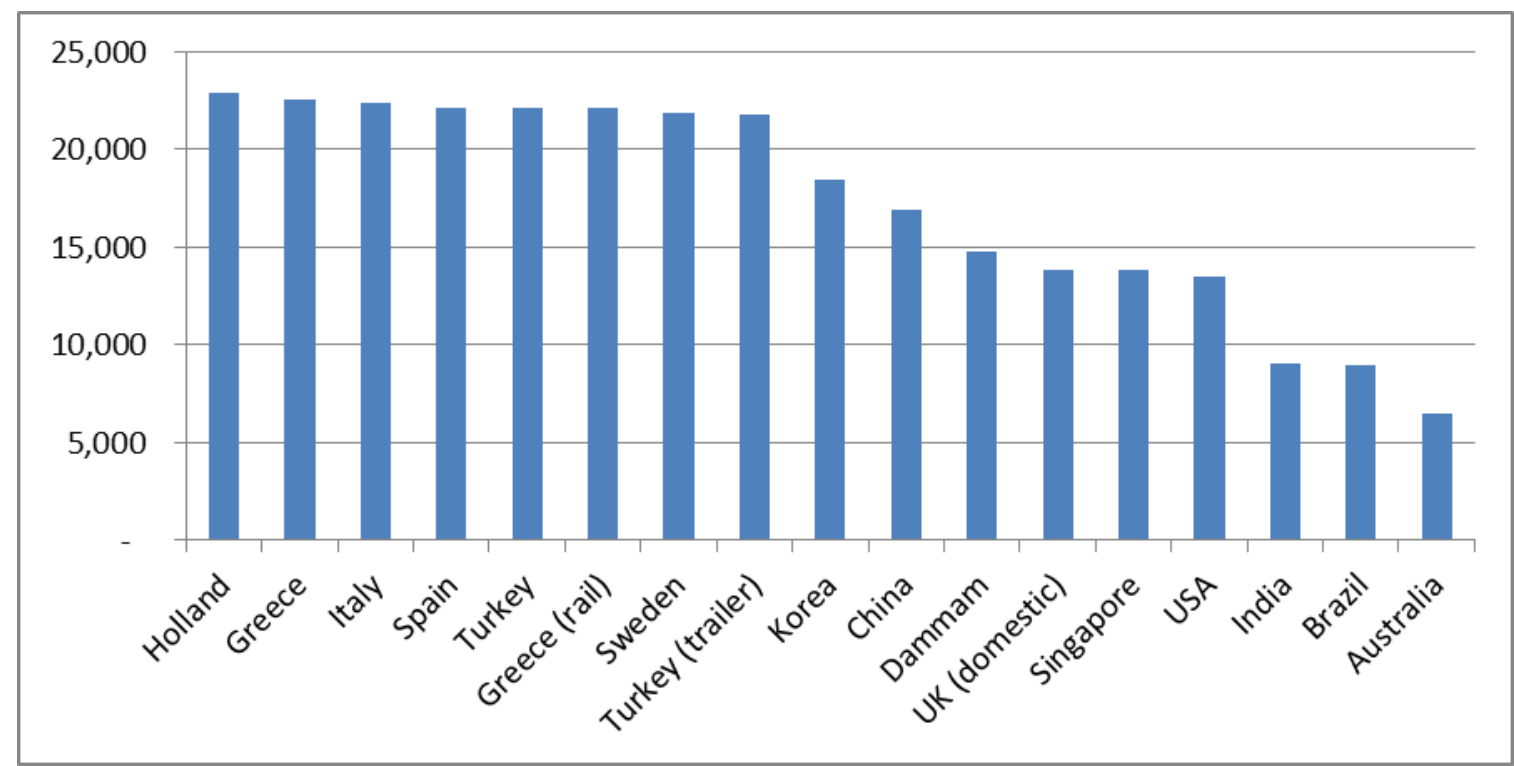

Figure 1: Average shipment weight in kg, for each route (case study 2).

\subsection{Road transport}

For the case of Full Truck Load (FTL) traffic, carbon emissions were calculated using Defra's emission factors in a vehicle.km basis. This was preferred to the Tonne.km basis since Tonne.km assumes percentage weight laden and average payload of $61 \%$ and $11.49 \mathrm{~T}$ respectively, which didn't match to our cases studies data, where the average weight laden is close to $100 \%$ for all upstream flows of case 1 (24.75 Tonnes) and also for most of the traffic in case 2.

In case 1, we used the full truck load value, which can be justified with the fact that every inbound transport voyage, either in Saudi Arabia, in Europe or in the UK is realised in a full truck with one single product, so the average weight and thus emissions are rather similar and simple to calculate, since we can assume that each voyage is similar in terms of average load and number of products. In case 2, even though most traffic was in full truck load, we used an extrapolation of Defra's values, using a linear regression approach. The emission factor for each load factor was weighted according to the truck load factor, as shown in figure 2. In the $\mathrm{x}$-axis we represent the truck load, and in the $\mathrm{y}$-axis the percentage of the full truck load emission factor that we apply for this specific load. For instance, an empty truck will generate $60 \%$ of the emissions of a fully loaded truck. 


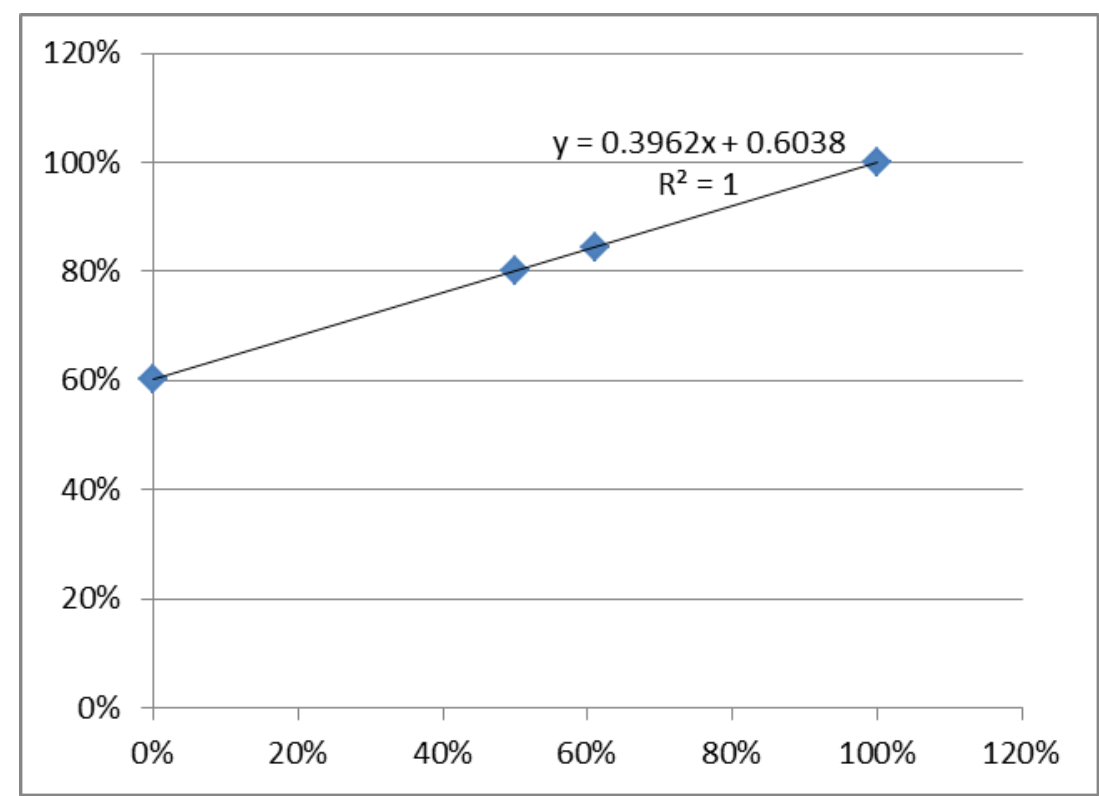

Figure 2: Extrapolation of Defra's Emission Factor (y-axis) versus Truck Load (x-axis), expressed as a percentage of the full truck load.

For final deliveries in case 1, from the UK distributor to the final customer, the exact measure is more complex, since deliveries are realised in Less than Truck Load (LTL) mode, to multiple customers, and with delivery routes that can change depending on the daily demand pattern. The difficulty here lies in defining the appropriate apportionment rule considering the available data as collected by the transport operator. The data provided covers one year of activity and does not track the routes used by the transporters for each of the delivery points. It doesn't cover either the truck load, or the share of this truck load used by our distributor (in case of multi-pick collection). Considering these data availability constraints, we have assessed the emissions from final deliveries using two approaches: the first one was to use the emission factors provided by Defra in a vehicle.km basis, and assuming a truck percentage weight laden of 61\%, the average UK truck load according to Defra (2011). Even though it does not represent the exact situation of each delivery, the use of an average here can be justified by the fact that the LTL deliveries are typically for multi-references and multi-drop deliveries. The application of this rule provided a result of $19.07 \mathrm{kgCO}_{2} \mathrm{e}$ per pallet for the final delivery. The approach is summarised in Table 3:

\begin{tabular}{|lc|}
\hline $\begin{array}{l}\text { Distance }(\mathrm{km}), \\
\text { average }\end{array}$ & 177 \\
\hline Truck Load $(\mathrm{kg})$ & 15,125 \\
\hline Truck Load (\%) & $61 \%$ \\
\hline kgCO2e $/ \mathrm{km}$ & 1.18643 \\
\hline $\begin{array}{l}\text { kg CO2e per } \\
\text { pallet }\end{array}$ & $\mathbf{1 9 . 0 7}$ \\
\hline
\end{tabular}

Table 3: Sample databox to calculate road traffic emissions

Where:

- Distance average: is the weighted average distance between the warehouse and the final customers (weighted by the tons delivered);

- $\quad$ Truck Load (kg): is the average truck load assuming 11 pallets carried; 
- $\quad$ Truck Load (\%): the resulting value of truck load (kg) expressed in \% of the truck capacity (assumed here at 25T). This result (61\%) is used as it represents the average UK truck load.

- $\quad \mathrm{kgCO}_{2} \mathrm{e} / \mathrm{km}$ : emission factor applied in $\mathrm{kgCO} 2 \mathrm{e}$ per vehicle.km;

- $\mathrm{kgCO}_{2} \mathrm{e}$ per pallet : $\mathrm{CO}_{2} \mathrm{e}$ emissions per pallet.

The second approach, used for case 1 only, consisted in asking the transporter for the emissions based on their actual fuel consumption. Theoretically, this approach is more accurate since we measure the actual fuel consumption from this transporter, but on the other hand the transporter wasn't able to provide a better customer apportionment method than a share based on the total tonnages delivered (which does not include the distance factor). For this reason, the Defra method was used and the transporter result was used to corroborate the result. The transporter average emissions were $16.93 \mathrm{CO}_{2} \mathrm{e}$ per pallet, which represent a difference of $11 \%$ when compared with the first approach. For FTL transport (upstream transport, in our case), the same data is applied, but using the appropriate emission factor for $100 \%$ truck load and using the exact distance between the origin and the destination points (which are known points, such as ports, factories or warehouses).

\subsection{Maritime emissions}

Emissions Factors from maritime traffic were also collected using Defra methodology, which are based on previous results obtained from the IMO's Greenhouse Gases Study published in 2009 (IMO, 2009), excepted for Ro-Pax vessels. Defra added the $\mathrm{CO}_{2} \mathrm{e}$ emission factors from $\mathrm{CH}_{4}$ and $\mathrm{N}_{2} \mathrm{O}$ to the IMO results. These emissions are expressed in $\mathrm{kgCO}_{2} \mathrm{e} / \mathrm{T}$.km. Just as for road traffic, emission factors from maritime traffic depend heavily on the vessel used for the journey, and the IMO has segmented emission factors based on the ship type and ship size. For an accurate End-to-End Supply Chain 'Carbon mapping', it is then imperative to collect such information about the vessels that are transporting the goods. When the company has an appropriate traceability by way of Bills of Lading (B/L) - which includes the Vessels name - it is possible to track the exact vessels specifications. When such information is not available, the information can be collected at the shipping company level. For the case study 1, for the service between Jeddah and the UK, a 5700 TEU container vessel was used as a reference. Due to the lack of Bill of Lading data, the use of information provided by AIS (Marine Traffic, 2012) was very useful to validate if vessels associated to shipping services were actually being used. Maritime distances were calculated on a port to port basis and were adjusted when the ports of call were not in the direct trajectory. Tonnages were directly provided by the distributor. Table 4 illustrates the databox used for maritime emissions.

\begin{tabular}{|lc|}
\hline Distance $(\mathrm{km})$ & 7,346 \\
\hline $\begin{array}{l}\text { Container Load } \\
(\mathrm{kg})\end{array}$ & 24,750 \\
\hline $\mathrm{kgCO2e} / \mathrm{T} . \mathrm{km}$ & 0.01957 \\
\hline $\begin{array}{l}\mathrm{kg} \text { CO2e per } \\
\text { pallet }\end{array}$ & $\mathbf{1 9 7 . 6 8}$ \\
\hline
\end{tabular}

Table 4: Sample databox to calculate maritime emissions

Where:

- Distance: is the maritime distance between the port of loading and port of unloading;

- Container Load: is the average load of a 40 foot container; 
- $\quad \mathrm{kgCO}_{2} \mathrm{e} / \mathrm{T} . \mathrm{km}$ : Emission Factor as provided by Defra (here, for a 5000-7999 TEU containership);

- $\mathrm{kgCO}_{2} \mathrm{e} / \mathrm{T} . \mathrm{km}$ : resulting $\mathrm{CO}_{2} \mathrm{e}$ emission per pallet for the voyage (considering the number of pallets per container provided in the product and packaging section).

\section{Port emissions}

At present, there is lack of any carbon emissions factors from port operations provided by Defra. But some UK ports have recently started to measure their carbon footprint operations (Mangan et al., 2011), and some information is thus available. However, the information is released at an aggregate value for all port operations, regardless of the type of cargo loaded and unloaded. This can be a problem since some cargo such as dry and liquid bulks tend to be much heavier than unitised cargo, causing then distortions if we apply a direct apportionment based on the weight only. To avoid this problem, two specific UK ports that actually measure their carbon emissions were used as reference ports: Felixstowe for containers, and Dover for Ro-Ro. The main reason that led to this choice is that these ports are specialised ports, with most traffic being containerships and Ro-Ro vessels respectively (DfT, 2010). We assumed then that the port activity profile was the best driver to assess emissions in the absence of detailed emissions by ship type. However, due to their small impact in the overall supply chain, as it was pointed by Mangan et al. (2011), we decided not to include port operations in the Value Stream Mapping illustration (Figure 3).

\subsection{Warehouse emissions}

Defra does not provide average emission factors for warehousing operations. It was then necessary to define an appropriate framework and identify the possible data sources for case 1 (case study 2 doesn't have warehousing operations in its scope). The information provided by the 3PL in charge of the warehousing operations in East Midlands was directly used. It was easy for the 3PL to calculate its overall electricity consumption and allocate to the distributor an appropriate share, based on the volume of products distributed belonging to each of its own customers. The resulting warehouse emissions, using the logistics provider data, are detailed in the databox below:

\begin{tabular}{|lr|}
\hline Days of Stock & 21 \\
\hline $\begin{array}{l}\text { Pallets } \\
\text { delivered }\end{array}$ & 12,828 \\
\hline $\begin{array}{l}\text { KWh / year } \\
\text { (electricity) }\end{array}$ & 22,800 \\
\hline $\begin{array}{l}\text { kgCO2/KWh } \\
\text { (Electricity UK) }\end{array}$ & 0.525 \\
\hline $\begin{array}{lr}\text { kgCO2/year } \\
\text { kgCO2 / pallet }\end{array}$ & 11,961 \\
\hline
\end{tabular}

Table 5: Sample databox used to calculate warehouse emissions

Where:

- Pallets delivered: is the annual number of pallets delivered for the distributor;

- kWh / year (electricity): the annual electricity consumed by the logistics provider allocated to the distributor (including logistics operations, such as the forklifts);

- $\mathrm{kgCO}_{2} / \mathrm{kWh}$ (Electricity UK): average emission factor applied for the electricity generation in the UK;

- $\mathrm{kgCO}_{2}$ /pallet : resulting $\mathrm{CO}_{2}$ emissions associated to each pallet delivered. 
For the warehousing operations situated outside of the UK - in Antwerp, Belgium - due to lack of information from the LSP, the same energy consumption as in the UK was used for operations, but using the electricity emission factor (in $\mathrm{kgCO}_{2} / \mathrm{kWh}$ ) from Belgium.

An alternative way to assess warehouse emissions was using results with square meters as a basis. We investigated a method based on an emission factor of $17.3 \mathrm{kgCO}_{2} / \mathrm{m}^{2} /$ year, provided by Cox and Graham (2010) for a typical large warehouse. The result, presented in Table 6 below, shows the flexibility allowed in the use in the databox.

\begin{tabular}{|lr|}
\hline Days of Stock & 21 \\
\hline $\mathrm{m}^{2} \mathrm{WH} /$ pallet & 1.0 \\
\hline $\begin{array}{l}\mathrm{kgCO} 2 / \mathrm{m}^{2} / \\
\text { year }\end{array}$ & 17.30 \\
\hline $\begin{array}{l}\mathrm{kg} \mathrm{CO2e} \mathrm{per} \\
\text { pallet }\end{array}$ & 1.00 \\
\hline
\end{tabular}

Table 6: Alternative possible databox to calculate warehouse emissions

Where:

- Days of stock: is average days of stock for this specific reference;

- $\mathrm{m}^{2} \mathrm{WH} /$ pallet: the average ratio of warehouse surface and pallet capacity;

- $\mathrm{kgCO}_{2} / \mathrm{m}^{2} /$ year: average annual $\mathrm{CO}_{2}$ emission factor for the warehouse per $\mathrm{m}^{2}$;

- $\mathrm{kgCO}_{2}$ /pallet: resulting $\mathrm{CO}_{2}$ emissions associated to each pallet delivered. The resulting emission is calculated by multiplying the three previous values and dividing by 365 (for example a pallet with 365 days of stock would provide here a result of $\left.17.3 \mathrm{kgCO}_{2}\right)$.

\subsection{The transport routes and their carbon footprint}

The list of possible transport routes was identified based on available options, and they were classified in three groups:

- "Ro-Ro routes": end-to-end routes from Saudi Arabia, with a warehousing operation in the supplier's facility in Antwerp (20 days of stock), then a transfer to the UK warehouse using one of the available Ro-Ro services;

- "Direct Lo-Lo routes": end-to-end routes with direct delivery to the UK with a transhipment operation in Continental Europe;

- "Direct routes": end-to-end route with a direct delivery to a UK port.

For each route thirteen generic steps were defined, and the total carbon footprint associated to a container delivery was then calculated for each route by adding the emissions generated at each point of the supply chain.

\section{Results and analysis}

\subsection{Case 1: End-to-End Inbound flows to the UK}

The analysis of case 1 data shows that Value Stream Mapping is a flexible tool that could be adapted to measure and analyse $\mathrm{CO}_{2}$ emissions with different calculation methods. The databox is an efficient tool to calculate carbon emissions using our approach based on 
emission factors. Figure 3 provides an illustration of the VSM for carbon footprint calculation, focused on the main operations.

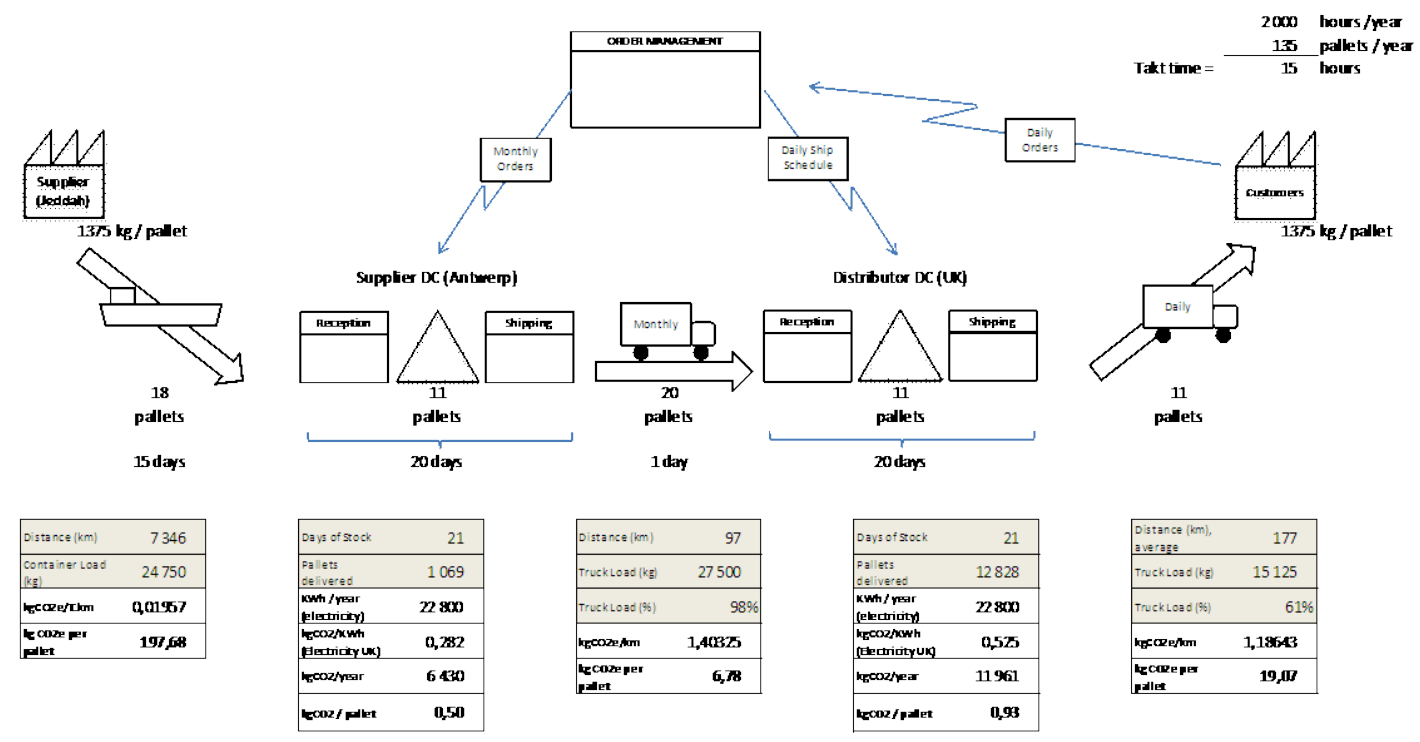

Figure 3: Current state Value Stream Mapping (illustration)

The end-to-end supply chain mapping shows that some Ro-Ro routes, such as 'Hoek Harwich', 'Ostend - Ramsgate', 'Dunkerque - Dover' and 'Calais - Dover' did not create any reason for deeper analysis compared to the current Ro-Ro route 'Zeebrugge - Purfleet', because they generated higher distances of travel if we consider the specific origin (Antwerp) and destinations (East-Midlands, Wales) in this case study. This latter route was then selected as the only option among all the possible 'Ro-Ro' routes. The calculation of the carbon footprint for the end-to-end supply chain shows that the maritime leg was the main source of $\mathrm{CO}_{2}$ emissions, as we can see in Figures 4 and 5. It also shows that the direct routes via Felixstowe (for the East Midlands warehouse) and Southampton (for the customer in Wales) were the best options to minimise carbon emissions to deliver the plastic products from Saudi Arabia to the customers in the UK. For the case company, among the existing routes from Continental Europe to the UK, Zeebrugge-Purfleet by Ro-Ro has the lowest carbon footprint, followed by container feedering through the Zeebrugge-Immingham service. It was also found that current apportionment choices used by Defra, based on tonnages of freight and passengers generate higher carbon footprints for routes using Ro-Pax vessels and thus penalise those routes. Indeed, unlike others emissions factors, provided by the IMO (2009), emission factors from Ro-Pax are provided by a different study, realised by Best Foot Forward for the Passenger Shipping Association (Defra, 2011). In this study, the average freight unit is estimated at 22.173 Tonnes whereas the average coupled passenger+car unit is estimated at 1.350 Tonnes, implying a significant $\mathrm{CO}_{2}$ allocation towards the freight activity in comparison to the passenger activity. In other words, we can suppose that even though most of the underperformance of Ro-Pax vessels is due to operational and design factors related to the passenger traffic (comfort, speed...), most of its $\mathrm{CO}_{2}$ emissions are apportioned to the freight activity. As a consequence, "Ro-Pax Freight” emissions factors are much higher than Ro-Ro freight emissions. 


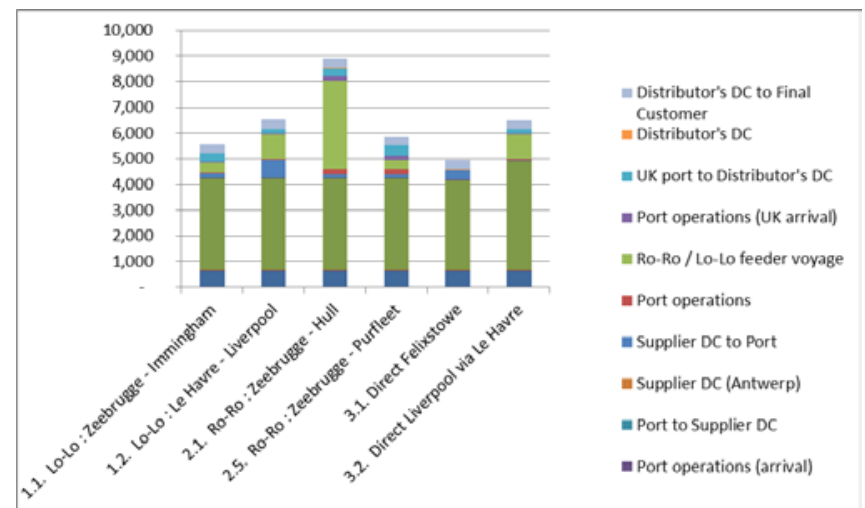

Figure 4: End-to-end $\mathrm{CO}_{2}$ emissions for different routes of palletized products

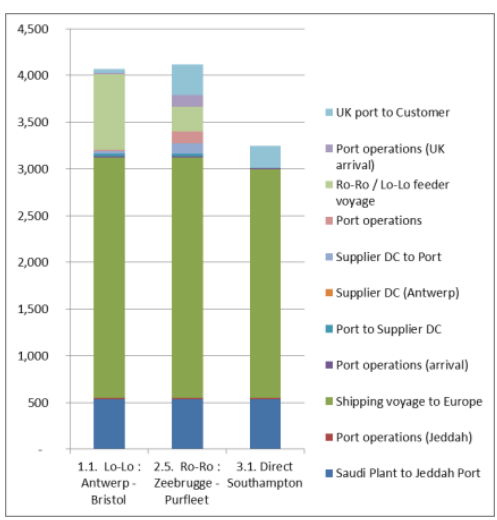

Figure 5: End-to-end $\mathrm{CO}_{2}$ emissions for different routes of bulk products

Comparing the current route (Zeebrugge - Purfleet) with the best route (direct to Felixstowe / Southampton), it can be seen in Table 7 that through direct routes to the UK ports, these emissions could be reduced by $16 \%$ to $21 \%$, depending on the products and routes.

\begin{tabular}{|c|c|c|c|c|c|}
\hline Stage (palletized products) & $\begin{array}{l}\text { Ro-Ro } \\
\text { route }\end{array}$ & $\begin{array}{l}\text { Direct } \\
\text { route }\end{array}$ & Stage (Bulk Products) & $\begin{array}{l}\text { Ro-Ro } \\
\text { route }\end{array}$ & $\begin{array}{l}\text { Direct } \\
\text { route }\end{array}$ \\
\hline Saudi Plant to Jeddah Port & 35 & 35 & Saudi Plant to Jeddah Port & 534 & 534 \\
\hline Port operations (Jeddah) & 2 & 2 & Port operations (Jeddah) & 17 & 17 \\
\hline Shipping voyage to Europe & 198 & 194 & Shipping voyage to Europe & 2570 & 2444 \\
\hline Port operations (arrival) & 2 & 2 & Port operations (arrival) & 17 & 17 \\
\hline Port to Supplier DC & 2 & - & Port to Supplier DC & 25 & - \\
\hline Supplier DC (Antwerp) & 1 & - & Supplier DC (Antwerp) & - & - \\
\hline Supplier DC to Port & 7 & 22 & Supplier DC to Port & 115 & - \\
\hline $\begin{array}{l}\text { Port operations } \\
\text { Ro-Ro / Lo-Lo feeder voyage }\end{array}$ & $\begin{array}{l}10 \\
20\end{array}$ & - & Port operations & 125 & - \\
\hline $\begin{array}{l}\text { Ro-Ro / Lo-Lo feeder voyage } \\
\text { Port operations (UK arrival) }\end{array}$ & $\begin{array}{l}20 \\
10\end{array}$ & - & Ro-Ro / Lo-Lo feeder voyage & 259 & - \\
\hline UK port to Distributor's DC & 21 & - & Port operations (UK arrival) & 125 & - \\
\hline Distributor's DC & 1 & 1 & UK port to Customer & 332 & 235 \\
\hline Distributor's DC to Final Customer & 19 & 19 & Distributor's DC & - & - \\
\hline Total emissions (kgCO2e/pal) & 326 & 275 & Total emissions (kgCO2e/Container) & 4119 & 3248 \\
\hline
\end{tabular}

Table 7: Detailed emissions, illustrations for bulk and palletized products, with the Ro-Ro route (Zeebrugge-Purfleet) and direct routes.

The analysis of the centre of gravity showed that the current location of the distribution centre was already near to the optimal even considering the impact that the direct deliveries could have in the total flow within the warehouse. This analysis was carried out using a Tons.km minimisation and is detailed in Table 8 , where we can see that the difference is only $-0.32 \%$. 
Year : 2010, sales data excluding candidate orders for direct deliveries

\begin{tabular}{|lrl|}
\hline Sales & 16,657 & Tonnes \\
\hline $\begin{array}{l}\text { Transport work (from } \\
\text { new centre of gravity) }\end{array}$ & $1,896,902$ & Tonnes.miles \\
\hline $\begin{array}{l}\text { Transport work (from } \\
\text { current 3PL location) }\end{array}$ & $1,903,004$ & Tonnes.miles \\
\hline
\end{tabular}

Difference (\%) - $\quad-0.32 \%$

Table 8: Total 2010 tonne.miles from the current 3PL location and from the new centre of gravity if direct deliveries were applied to all candidate orders.

The methodology used in this research enables the distribution company to exchange information about emissions with the partners in the supply chains including logistics service providers. From a management perspective for the case company, direct sailing to the UK ports will have an impact on inventory management practices with reference to a need to recalculate the safety stocks for the new delivery times for the customers. On the other hand it should have a limited impact on order sizes, since this is unlikely to change with the suggested route of direct sailing to the UK.

To work out the industry impact, the 4-step practical approach to achieve "Competitive Advantage on a Warming Planet” proposed by Lash and Wellington (2007) can be employed:

- $\quad$ step 1: Quantify your “carbon footprint”

- $\quad$ step 2: Assess your carbon-related risks and opportunities

- $\quad$ step 3: Adapt your business

- $\quad$ step 4: Do it better than rivals.

Case company 1 has applied steps 1 to 3 based on the analysis of this research and found it extremely useful mainly in anticipation of regulatory, supply chain and reputation risks. No comparison with rivals supply chains has been carried out by them yet.

\subsection{Case 2: Outbound distribution flows from the UK}

The analysis in case 2 shows that the total emission factor of routes from the UK to southern European destinations such as Turkey, Spain and Italy could be significantly higher than the ones to distant overseas countries, as can be seen in Figure 6. This is due to the use of road transport as the main transport mode for the near destinations and maritime transport for the distant destinations, as illustrated in Table 2. 


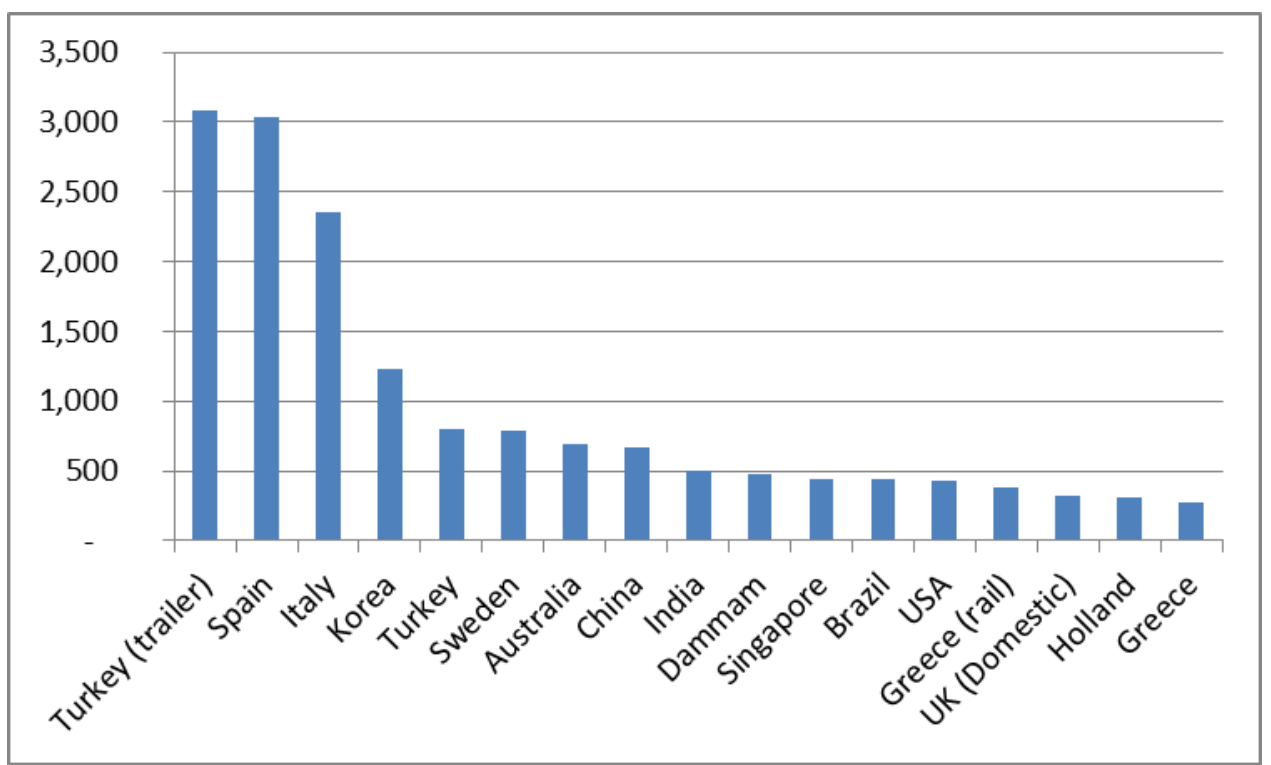

Figure 6: Total emissions in $\mathrm{kgCO}_{2}$ per tonne of cargo for each route analysed for case 2.

It is important to note that those southern European destinations are among the ones with the best load factor, suggesting that under identical product density and package specifications, the difference between their per unit carried emissions and those for distant destinations could actually be even higher.

Two of the destinations in this case analysis are delivered via two different routes: Turkey and Greece. The analysis of the flows for Turkey supports the idea that delivering southern European destinations (here, Spain and Italy) via maritime means is a major lever of emissions reductions. The analysis of flows for Greece showed that a transport by maritime means, from a local port (here, Teesport) with transhipment in Antwerp was slightly more efficient than transport by rail to Felixstowe for a direct maritime service to Greece.

In terms of industrial impact and change, the company in case 2 applied step 1 of the Lash and Wellington (2007) approach while the researchers were working on the case. They were surprised by the outcome ('local' destinations are the largest contributors to $\mathrm{CO}_{2}$ emissions) and became aware of the main sources of emissions in their supply chain. Further steps for the company should identify solutions to reduce emissions from those routes and implement changes.

\section{Discussion and conclusions}

The research presented in this paper has attempted to map the end-to-end carbon footprint for given supply chains by two case companies in two different industrial sectors. The results from both cases demonstrated that in the case of distant overseas countries as origins or destinations, the maritime leg remains the main part of the end-to-end supply chain's carbon emissions. Even though maritime transport is more efficient than other modes of transport for emissions, it is still the important focus for efforts concerning the reduction of emissions as nearly $90 \%$ of international trade is using maritime transport.

The results from Case 2 for southern European destinations suggest that local sourcing does not always have lower emissions benefit when different transport modes are used. 
In both cases analysed in this paper, it appeared that the data availability, reliability and the apportionment rule play crucial roles in the modelling process, and results must be analysed with regard to the restrictions and approximations used. For working out the emission factors, we have mainly used Defra's data, but if we look at all the datasets employed, they can be classified with the following levels of detail:

- Level 1: International averages or national averages extended to other countries (used for example for international shipping and foreign road transport);

- Level 2: National averages applied to the corresponding country (used for example for UK road transport and Ro-Ro shipping);

- Level 3: Company benchmarks from equivalent business (used for the port activity, or - as a possible alternative - for warehousing);

- Level 4: Company averages (used in case 1 to corroborate final distribution values);

- Level 5: Company averages for this specific business (used for warehousing in the UK, and the homogeneity of warehousing activity made it possible for the LSP to calculate it).

In our opinion, in complex supply chains, such as used in the case studies presented in this paper, the availability of more accurate data (exact emissions or fuel/energy consumptions for each logistics operation) is difficult. The use of averages and standard emission factors are part of the optimisation process and such constraints have an impact on the range of optimisation study conclusions. Also, this approach is perhaps the only way to use methods such as VSM with calculation rules that are simple, and thus, more likely to be applied by logistics providers. GHG Protocol (2011) points out in its guidelines the importance of formalising the business goals of each study before starting any modelling process. We think that this guideline is key in helping to build models with enough accuracy in the areas where optimisation levers are applicable, and with simpler rules in areas that would not have an impact in the final results and conclusions. The tools recommended in this paper should not be seen as accurate GHG measurement methods, but as tools that aim to help companies to make steps in the right direction for achieving $\mathrm{CO}_{2}$ emission reductions.

\section{References}

BSR (2011) "Beyond the Factory Gates: How Brands Improve Supply Chain Sustainability Through Shipping and Logistics”,

Carbon Disclosure Project (2012) “CDP Supply Chain report 2012”, London: Carbon

Disclosure Project.

Cox, S., Graham, L. (2010) “Sustainability Measured: Gauging the Energy Efficiency of European Warehouses”, in Prologis Research Insights, Spring 2010.

Defra (2011) “Guidelines to Defra/DECC’s GHG Conversion Factors for Company Reporting: Methodology Paper for Emission Factors”, London: Defra.

Department for Transport (2010) “Maritime Statistics 2009”, London: Transport Statistics Publications. 
Edwards, J., McKinnon, A., Cullinane, S., (2009) “Carbon Auditing the 'Last Mile': Modelling the Environmental Impacts of Conventional and Online Non-food Shopping", Green Logistics, Edinburg: Heriot-Watt University.

GHG Protocol (2011) “Corporate Value Chain (Scope 3) Accounting and Reporting Standard”, USA: World Resources Institute and World Business Council for Sustainable Development.

International Maritime Organisation (2009) “Second IMO GHG Study”, London: IMO.

International Maritime Organisation (2012) "Reduction of GHG Emissions from Ships: GHG Emissions from Existing Vessels”, MEPC 63/5/13, submitted by World Wide Fund for Nature (WWF) and Clean Shipping Coalition (CSC), London: IMO.

Lash, J., and Wellington, F. (2007) “Competitive Advantage on a Warming Planet”, Harvard Business Review, March 2007.

Leonardi, J. and Browne, M. (2010), “A method for assessing the carbon footprint of maritime freight transport: European case study and results", International Journal of Logistics Research and Applications, Vol. 13: 5, pp. 349 - 358.

Mangan, J., Lalwani, C., Gibbs, D., Rigot-Muller, P. and Bennett, M. (2011) "Logistics and Low Carbon Shipping”, in LCS 2011 International Conference Proceedings, University of Strathclyde, Glasgow: O. Turan and A. Incecik.

Marine Traffic (2012). Live Ship Maps - AIS. [online] Available at:

$<$ http://www.marinetraffic.com/ais/default.aspx> [Last accessed 29 March 2012 ].

Miyoshi, C. and Mason, K., "The carbon emissions of selected airlines and aircraft types in three geographic markets”, in Journal of Air Transport Management, Volume 15, Issue 3, May 2009, pp. 138-147.

Norton, A. (2007) "Sustainable Value Stream Mapping as a Technique for Analysing and Reducing Waste in the UK Chilled Food Sector”, PhD Thesis, University of London, Imperial College, Centre for Environmental Policy.

Olson, E. (2009) "Better Green Business: Handbook For Environmentally Responsible and Profitable Business Practices”, USA: Pearson Education Inc.

Ramudhin, A., Chaabane, A., Kharoune, M., Paquet, M., "Carbon Market Sensitive Green Supply Chain Network Design”, Proceedings of the 2008 IEEE IEEM, pp.1093-1097.

Rizet, C., Browne, M., Leonardi, J., Allen, J. and Cornelis, E. (2008) "Energy efficiency and greenhouse gas emissions of different supply chains: a comparison of French, UK and Belgian cases". Paper presented at the European Transport Conference, 06-08 October 2008. The Netherlands:Noordwijkerhout.

Rother, M. and Shook, J. (2009) "Learning to See”, version 1.4, USA: Lean Enterprise Institute. 
Simons, D., Mason, R. (2003) "Lean and Green: doing more with less", in ECR Journal, Vol.3, No.1, pp.84-91, Spring 2003.

Sundarakani, B., de Souza, R., Goh, M., Wagner, S., Manikandan, S. (2010) “Modelling carbon footprints across the supply chain”, in International Journal of Production Economics, No. 128, pp. 43-50.

Wiedmann, T. and Minx, J. (2008). A Definition of 'Carbon Footprint'. In: C. C. Pertsova, Ecological Economics Research Trends: Chapter 1, pp. 1-11, Nova Science Publishers, Hauppauge NY, USA. Available at <http://www.censa.org.uk/docs/ISA-UK_Report_0701_carbon_footprint.pdf $>$.

Windsor, S. (2010) “An Introduction to Green Process Management”, USA: ASQ Quality Press. 